\title{
Root canal retreatment using Reciproc and ProTaper universal systems. Comparative evaluation
}

\author{
Reluarea tratamentului endodontic cu sistemele Reciproc şi ProTaper universal de \\ retratament. Evaluare comparativă
}

\begin{tabular}{|c|}
\hline $\begin{array}{c}\text { Sînziana Adina Scărlătescu }{ }^{1} \text { Irina Maria Gheorghiu², } \\
\text { Anca-Nicoleta Temelcea }{ }^{3} \text {, Paula Perlea }{ }^{1}\end{array}$ \\
\hline $\begin{array}{c}\text { 1Disciplina de Endodonţie, Facultatea de Medicină Dentară, UMF „Carol Davila“, Bucureşti } \\
\text { 2Disciplina de Odontoterapie Restauratoare, Facultatea de Medicină Dentară, } \\
\text { UMF „,Carol Davila“, Bucureşti } \\
\text { 'Disciplina de Tehnică Dentară, Facultatea de Moaşe şi Asistenţă Medicală, } \\
\text { UMF „Carol Davila“, Bucureşti }\end{array}$ \\
\hline
\end{tabular}

\begin{abstract}
The aim of this study was to compare the efficacy of two rotary retreatment systems in removing remnants of filling materials during root canal retreatment.

Materials and methods. 20 lower premolar canals were shaped by ProTaper next up to F2 and .06 taper and filled using cold lateral condensation of gutta-percha. These were divided into 2 groups $(n=10)$ according to the retreatment systems. There were compared the times of retreatment and the radiographic quality of retreatment based on scores attributed to areas of residual material.

Results. Reciproc system (VDW GmbH, München, Germany) led to a medium retreatment time of 5.75 seconds per canal and $90 \%$ of the canals showed less than $20 \%$ remnants on the canal wall. ProTaper retreatment system (Dent-sply - Sirona, Switzerland) led to a medium retreatment time of 7.15 seconds and $60 \%$ of the canals showed less than $20 \%$ remnants.

Conclusion. Within the limitation of this study, Reciproc system proved to be more rapid and efficient than ProTaper Retreatment system.
\end{abstract}

Keywords: retreatment, reciproc movement, Reciproc system, ProTaper system

\section{REZUMAT}

Scopul acestui studiu a fost compararea a două sisteme rotative în ceea ce priveşte eficienţa îndepărtării gutapercii din canalele radiculare în timpul reluării tratamentului endodontic.

Materiale şi metode. 20 de canale ale premolarilor inferiori au fost preparate folosind ProTaper Next până la acul F2 şi conicitate .06 şi obturate prin condensare laterală la rece a gutapercii. Acestea au fost împărţite în 2 grupe (n = 10) în funcţie de sistemul cu care s-a dezobturat. S-au comparat timpii de dezobturare şi s-a făcut analiza radiologică a calităţii dezobturării pe baza scorurilor atribuite ariilor de material remanent.

Rezultate. Sistemul Reciproc (VDW GmbH, München, Germania) a înregistrat un timp mediu de dezobturare de 5,75 minute per canal, iar $90 \%$ dintre canale au prezentat mai puţin de $20 \%$ material remanent pe pereţii canale-lor radiculare. Sistemul ProTaper de retratament (Dentsply - Sirona, Elveţia) a înregistrat un timp mediu de 7,15 minute per canal, iar $60 \%$ dintre canale au prezentat mai puţin de $20 \%$ material remanent.

Concluzii. Ţinând cont de limitele acestui studiu, sistemul Reciproc s-a dovedit a fi mai rapid şi mai eficient decât sistemul Protaper de dezobturare.

Cuvinte cheie: reluarea tratamentului, mişcare reciprocă, sistemul Reciproc, sistemul ProTaper

\section{INTRODUCERE}

Succesul pe termen lung al tratamentului de canal depinde de prevenirea reinfectării spaţiului endodontic. Rata de supravieţuire a dinţilor pe arcadă în cazul retratamentului conservator este cuprinsă între 56 şi $88 \%$ (1). Rezultatele variază în funcţie de vârsta pacientului, de dintele abordat, de posibilitatea de îndepărtare a restaurării coronare pentru a avea acces la camera pulpară şi de posibilitatea de a repara erorile patologice şi iatrogene. Perforaţiile preoperative, morfologia radiculară, prezenţa sau absenţa preoperatorie a leziunilor periapicale, tipul de radiotransparenţă (conturată sau difuză), calita- 
tea materialelor de obturaţie radiculară şi tipul de restaurare coronară sunt factori de prognostic importanţi pentru succesul retratamentului $(2,3)$.

Reluarea tratamentului endodontic este indicată atunci când sistemul endocanalicular se reinfectează. Procedura presupune îndepărtarea în totalitate a obturaţiei de canal, dezinfectarea şi reobturarea canalelor printr-o obturaţie de canal completă, omogenă, etanşă tridimensional şi stabilă în timp. Cele mai folosite materiale de obturaţie de canal la ora actuală sunt gutaperca şi cimenturile de sigilare. Îndepărtarea completă a acestora din canalul rdicular este o procedură dificilă şi cronofagă. Pentru realizarea acestui deziderat, sunt disponibile mai multe tehnici şi instrumente, cum ar fi instrumentarul manual şi rotativ, aparatura ultrasonică şi laserul care, totuşi, nu reuşesc să îndepărteze complet nici ele materialul de obturaţie (4).

Pentru a facilita curăţarea şi modelarea canalelor radiculare, au fost concepute o serie de intrumente rotative din nichel-titan cu vârfuri netăietoare, faţete de ghidare radiale, conicităţi diferite şi pas de dimensiuni variate. Unul dintre aceste sisteme este sistemul ProTaper de dezobturare (Dentsply Sirona, Elveţia), care conţine 3 ace: D1, D2 şi D3. Ele au $16 \mathrm{~mm}$ (D1), $18 \mathrm{~mm}$ (D2) şi $22 \mathrm{~mm}$ (D3) şi sunt indicate pentru îndepărtarea gutapercii din treimea coronară, mijlocie şi, respectiv, apicală. Diametrele vârfurilor pentru D1, D2, D3 sunt $0,30 \mathrm{~mm}$, $0,25 \mathrm{~mm}$ şi $0,20 \mathrm{~mm}$, cu conicităţi de $9 \%, 8 \%$ şi 7\%. În timp ce celelalte au vârful netăietor, D1 are vârful activ pentru penetrarea iniţială în canalul radicular.

Un alt sistem din ce în ce mai folosit în reluările de tratament este sistemul Reciproc (VDW GmbH, München, Germania) care include 3 ace (R25, R40, R50), fiecare alegându-se în funcţie de dimensiunile iniţiale ale canalului radicular. Pe secţiune transversală, acestea prezintă formă de $\mathrm{S}$ şi sunt confecţionate din Ni-Ti M- wire, făcându-le mai flexibile şi mai rezistente la oboseala ciclică. Tehnica de utilizare a acestui sistem este foarte simplă - şi anume aceea de a folosi un singur ac pentru prepararea canalului radicular, fără a fi necesară utilizarea acelor manuale. Importanţa sistemului reciproc se referă la eficienţa acestuia, la care se adaugă riscul scăzut de accidente şi incidente, datorită procesului de fabricare şi datorită faptului că sunt instrumente de unică folosinţă. În cazul reluării de tratament, majoritatea specialiştilor preferă sistemul Reciproc clasic, datorită rigidităţii acestuia, în comparaţie cu sistemul Reciproc Blue (5).

Scopul acestui studiu a fost compararea a două sisteme rotative în ceea ce priveşte eficienţa îndepărtării gutapercii din canalele radiculare în timpul reluării tratamentului endodontic. Au fost urmărite şi evaluate timpul necesar atingerii lungimii de lucru, calitatea dezobturării şi accidentele survenite în cursul dezobturării.

\section{MATERIALE ŞI METODE}

În studiu au intrat 20 de premolari inferiori integri, extraşi de la diverşi pacienţi din motive parodontale, fără tratament endodontic. S-a creat cavitatea de acces cu o freză sferică diamantată de turbină (nr. 806.314.012, Komet Brasseler, Lemgo, Germany). S-a realizat permeabilizarea dinţilor cu ace Kerr file ISO 10 pe toată lungimea canalelor. Lungimea de lucru a fost determinată astfel: s-a introdus un ac K file nr. 15 în canalul radicular şi s-a măsurat distanţa dintre vârful cuspidului vestibular şi foramenul apical, în momentul în care vârful acului a fost vizibil la foramenul apical. Din această dimensiune s-a scăzut $1 \mathrm{~mm}$.

Tratamentul mecanic de canal s-a realizat folosind tehnica crown-down cu instrumentar rotativ. Toate canalele au fost preparate folosind ProTaper Next până la acul F2 şi conicitate .06. Preparaţia a fost realiată cu motorul endodontic X-Smart (Dentsply Sirona) la viteza de turaţie $300 \mathrm{rpm}$. În cursul lărgirii, s-au efectuat lavaje cu hipoclorit de sodiu 2,5\% după fiecare ac folosit şi soluţie EDTA 17\% (Cerkamed, Polonia). După uscarea canalelor cu conuri de hârtie, toţi dinţii au fost obturaţi prin tehnica de condensare laterală la rece folosind conuri de gutapercă şi ciment de sigilare (Adseal, Meta - Biomed). Dinţii au fost obturaţi coronar cu Citodur hard şi au fost menţinuti în condiţii de umiditate de $100 \%$ la $37^{\circ} \mathrm{C}$ pentru 7 zile, pentru a permite priza completă a sealerului şi a imita condiţiile din cavitatea bucală. Apoi, dinţii a fost împărţiţi aleatoriu în 2 grupuri ( $\mathrm{n}=10)$, în funcţie de sistemul rotativ cu care au fost dezobturaţi.

Grupul 1: sistemul ProTaper Universal de dezobturare

Grupul 2: sistemul Reciproc 


\section{Grupul 1: ProTaper Universal de dezobturare}

Canalele radiculare au fost instrumentate într-o manieră crown-down la o turaţie de 500 rpm, după recomandările producătorului. Acul ProTaper D1 a fost folosit pentru îndepărtarea materialului de obturaţie din porţiunea coronară, în timp ce treimile mijlocie şi apicală au fost instrumentate folosind acele D2 şi D3. D2 şi D3 au fost folosite printr-o mişcare de pensulare cu aplicare de presiune laterală. ProTaper D3 a fost folosit pe toată lungimea de lucru a canalului radicular. În continuare, pentru definitivarea preparaţiei, s-a introdus acul F2 prin mişcări de ciugulire pe toată lungimea de lucru.

\section{Grupul 2: Sistemul Reciproc}

$\mathrm{Cu}$ acul R25 s-au realizat câte 3 mişcări de ,înainte- înapoi“, urmate de irigarea canalelor radiculare cu hipoclorit de sodiu 5,25\%. Presiunea aplicată a fost mică, iar amplitudinea mişcării nu a depăşit 3-4 mm. După fiecare set de mişcări s-a realizat lavajul canalelor radiculare cu hipoclorit de sodiu $2,5 \%$ (aproximativ $6 \mathrm{ml}$ ).

În ambele grupuri, au fost folosite doar acele de dezobturare fără folosirea solvenţilor. Acele au fost curăţate de resturi de material înainte de reintroducerea în canal. Retratamentul a fost considerat complet atunci când pe ultimul instrument care a atins lungimea de lucru nu au mai fost observate resturi de gutapercă sau ciment de sigilare. După ultima instrumentare, canalele au fost spălate abundent cu hipoclorit de sodiu şi uscate cu conuri de hârtie.

Timpul total, inclusiv irigarea, necesar pentru îndepărtarea materialul din canalul radicular pe toată lungimea de lucru a fost înregistrat pentru fiecare canal folosind un cronometru. După dezobturare, toţi dinţii au fost radiografiaţi din incidenţă mezio-distală. A fost considerată aria totală a canalului ca fiind $100 \%$, iar ariile de materiale radioopace au fost exprimate ca un procent din aria canalului. Pentru cuantificarea rezultatelor obţinute s-a utilizat o grilă de punctaj stabilită de Kfir şi colab. 2012 (6).

Scorurile au fost împărţite în 3 categorii reprezentative:

1 - canal curat $(0-5 \%$ din aria canalului acoperită de reziduuri observate pe imaginea radiologică)
2 - canal cu reziduuri moderate $(6-20 \%$ din aria canalului acoperită de reziduuri observate pe imaginea radiologică)

3 - canal cu reziduuri în cantitate mare (peste $21 \%$ din aria canalului acoperită de reziduuri observate pe imaginea radiologică)

\section{REZULTATE}

\section{Timpul de dezobturare}

Timpul mediu de atingere al lungimii de lucru în cele două grupuri a fost diferit. Se poate observa că timpul total de lucru cu sistemul Reciproc a fost mai mic decât timpul obţinut cu sistemul ProTaper Universal de retratament (tabelul 1).

TABELUL 1. Timpii medii, valorile maxime şi minime per canal necesare dezobturării

\begin{tabular}{|l|c|c|c|}
\hline \multicolumn{1}{|c|}{$\begin{array}{c}\text { Tehnica de } \\
\text { dezobturare }\end{array}$} & $\begin{array}{c}\text { Medie per } \\
\text { canal }\end{array}$ & $\begin{array}{c}\text { Valoarea } \\
\text { maximă }\end{array}$ & $\begin{array}{c}\text { Valoarea } \\
\text { minimă }\end{array}$ \\
\hline $\begin{array}{l}\text { Grupul } 1-\text { sistemul } \\
\text { ProTaper de } \\
\text { retratament }\end{array}$ & 7,14 minute & 9,50 minute & 5,40 minute \\
\hline $\begin{array}{l}\text { Grupul } 2-\text { sistemul } \\
\text { Reciproc }\end{array}$ & 5,75 minute & 7,25 minute & 3,15 minute \\
\hline
\end{tabular}

\section{Calitatea dezobturării}

Folosind sistemul Reciproc, s-au obţinut mai multe canale cu scor 1 ( 5 canale), comparativ cu sistemul ProTaper de dezobturare (4 canale) (tabelul 2). Totodată, în urma acţiunii sistemului Reciproc s-au observat mai puţine arii de materiale radioopace remanente pe radiografiile după dezobturare (fig. 1, 2, 3) faţă de ariile remanente rezultate după dezobturarea cu acele ProTaper (fig. 4, 5, 6).

TABELUL 2. Scoruri obținute în urma acțiunii celor 2 sisteme de dezobturare

\begin{tabular}{|l|l|l|l|}
\hline Metoda de dezobturare & \multicolumn{1}{c|}{ Scor $\mathbf{1}$} & \multicolumn{1}{c|}{ Scor $\mathbf{2}$} & \multicolumn{1}{c|}{ Scor $\mathbf{3}$} \\
\hline Grupul 1- sistemul & 4 canale & 2 canale & 4 canale \\
ProTaper de retratament & $(40 \%)$ & $(20 \%)$ & $(40 \%)$ \\
\hline Grupa 2 - sistemul & 5 canale & 4 canale & 1 canal \\
Reciproc & $(50 \%)$ & $(40 \%)$ & $(10 \%)$ \\
\hline
\end{tabular}

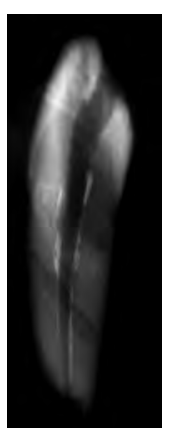

FIGURA 1. Dezobturare sistem Reciproc, scor 2 


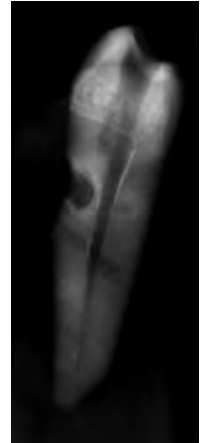

FIGURA 2. Dezobturare sistem Reciproc, scor 1

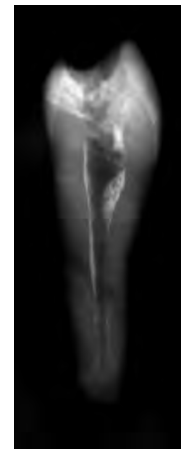

FIGURA 3. Dezobturare sistem Reciproc, scor 2

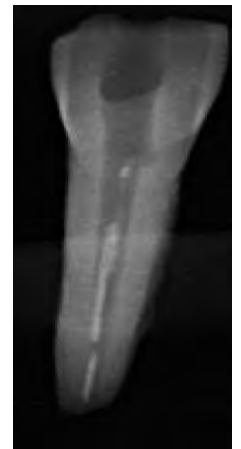

FIGURA 4. Dezobturare sistem ProTaper scor 3

\section{Accidentele survenite în cursul dezobturării}

În cursul manoperelor de dezobturare, în grupul $1 \mathrm{~s}$-a produs ruperea vârfului unui ac D3 în porţiunea apicală.

\section{DISCUȚII}

Reluarea tratamentului endodontic este de multe ori necesară din cauza eşecului tratamentului iniţial, ca urmare a unor factori diverşi: izolare neadecvată, cavitate de acces incorect efectuată, insuficientă preparare şi antiseptizare a canalelor radiculare, obturaţie de canal incompletă sau cu depăşire fără sigilarea apexului, ruperea unor instrumente şi blocarea traseului canalului radicular, canale radiculare netratate, diverse accidente şi incidente care pot

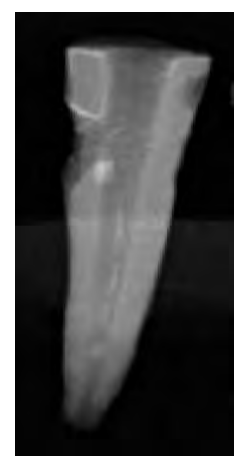

FIGURA 5. Dezobturare sistem ProTaper, scor 2

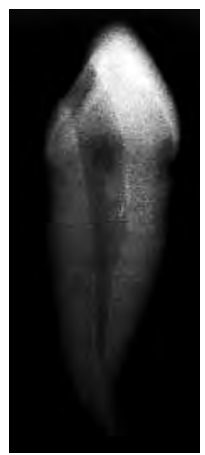

FIGURA 6. Dezobturare sistem ProTaper, scor 1

surveni în cursul preparaţiei, precum şi o restaurare coronară deficitară (7). Unele dintre cele mai folosite instrumente pentru îndepărtarea materialelor de obturaţie de canal la ora actuală sunt sistemele Reciproc şi ProTaper.

După analiza imaginilor radiologice, în cazul ambelor metode s-a înregistrat material de obturaţie neîndepărtat, însă în cazul dezobturării cu sistemul Reciproc scorurile obţinute au fost uşor superioare sistemului ProTaper de dezobturare. $\mathrm{Nu}$ s-a încercat diferenţierea între materialele remanente de obturaţie de canal, pentru că imaginile radiologice sunt bidimensionale şi nu pot semnala diferenţele dintre sealer şi gutapercă (8).

Dezobturarea cu acele ProTaper de retratament a arătat $\mathrm{o}$ cantitate mai mare de material remanent de-a lungul canalului radicular şi, de asemenea, a fost o metodă care a necesitat un timp mai îndelungat comparativ cu sistemul Reciproc. Rezultate similare au obţinut şi Zuolo şi colab. (2013) (9). Aceştia au efectuat un studiu în care au concluzionat că mişcarea reciprocă este mai eficientă decât mişcarea continuă în îndepărtarea materialelor de obturaţie de canal, datorită ariei de contact mai mare a acelor cu gutaperca. Acele cu mişcare continuă stabilesc un unghi de contact mai mic cu guta- 
perca şi, deoarece nu există decât o mişcare în sensul acelor de ceas, sistemul reuşeşte să disloce o cantitate mai mică de material, în special la nivel coronar (9).

În studiul pe care 1-am efectuat, timpul de lucru necesar dezobturării cu sistemul ProTaper rotativ de dezobturare a fost mai mare comparativ cu timpul de lucru realizat cu sistemul Reciproc, atât în ceea ce priveşte valorile maxime şi minime, cât şi media per canal de dezobturare. Un alt motiv pentru această diferenţă de timp ar putea fi numărul mai mare de instrumente - 3 la ProTaper, faţă de 1 la sistemul Reciproc.

Sistemul Protaper Universal de dezobturare s-a dovedit, totuşi, a fi eficient în îndepărtarea materialului de obturaţie de canal, şi aceasta datorită configuraţiei acelor. Aceste caracteristici pot permite instrumentelor să taie nu numai gutaperca, dar şi un strat superficial de dentină. De asemenea, acest sistem este capabil să îndepărteze o cantitate mare de material de obturaţie datorită unghiului de tăiere negativ ce nu are o acţiune de netezire a gutapercii, ci de tăiere (6).

\section{BIBLIOGRAFIE}

1. Hepworth M.J., Friedman S. Treatment outcome of surgical and non-surgical management of endodontic failures. J Can Dent Assoc 1997; 63:364-371.

2. Barone C, Dao T, Basrani B, Wang N, Friedman S. Treatment outcome in endodontics: The TorontoStudy - Phases 3, 4, and 5 : Apical surgery J Endod 2010; 36(1):28-35.

3. Friedman S, Abitbol S, Lawrence PH. Treatment outcome in endodontics: The Toronto Study. Phase 1: Initial treatment. J Endod 2003; 29(12):787-792.

4. Capar ID, Arslan H, Ertas H, Geok T, Saygılı G. Effectiveness of ProTaper Universal retreatment instruments used with rotary or reciprocating adaptive motion in the removal of root canal filling material. Int Endod J, 2015; 48:79-83.

5. de Azedevo Rios M, Villela AM, Sanches Cunha R, Cortez Velasco R, de Martin AS, Shoji Kato A, da Silveira Bueno CE. Efficacy of 2 Reciprocating systems compared with a rotary retreatment system for gutta-percha removal. J of Endod 2014; 40(4):453-546.

6. Kfir A, Tsesis I, Yakirevich E, Matalon S, Abramovitz I. The efficacy of five techniques for removing root filling material: microscopic versus radiographic evaluation. Int End J, 2012; 45: 35 - 41.
Îndepărtarea completă a reziduurilor de sealer şi gutapercă de pe pereţii canalelor radiculare nu a fost posibilă prin niciuna dintre tehnicile utilizate, ceea ce a fost consemnat şi de Wilcox şi colab. (10) şi Taşdemir şi colab. (11).

\section{CONCLUZII}

Ambele grupuri de dinţi experimentali au prezentat material de obturaţie şi gutapercă restantă în urma reluării de tratament endodontic. Ţinând cont de limitele acestui studiu, sistemul Reciproc s-a dovedit a fi mai mai eficient datorită scorurilor superioare obţinute şi mai rapid în îndepărtarea materialului de obturaţie restant. Studii experimentale şi tehnologice viitoare sunt necesare pentru a evalua eficienţa diverselor mişcări cinematice în scopul reluării tratamentului endodontic.

\section{Notă}

Toţi autorii au contribuţii egale în realizarea acestui articol.
7. Dhanyakumar NM, Ajit MN . A comparative analysis of efficacy of retreating the root canal using rotary files, in rotational motion or reciprocative adaptive motion and reciprocating single file system: an in vitro study . J of Dent, 2017; 9(1):1-6.

8. Schirrmeister JF, Werbas KT, Meyer KM, Altenburger MJ, Hellwig E. Efficacy of different rotary instruments for gutta-percha removal in root canal retreatment. $J$ of Endod, 2006; 32:469-472.

9. Zuolo AS, Mello JE, Cunha RS, Zuolo ML, Bueno CES. Efficacy of reciprocating and rotary techniques for removing filling material during root canal retreatment. Int Endod J, 2013; 46:947-953.

10. Wilcox LR, Krell KV, Madison S, Rittman B. Endodontic retreatment: Evaluation of gutta-percha and sealer removal and canal reinstrumentation. $J$ of Endod, 1987; 13:453-457.

11. Taşdemir T, Er K, Yildirim T, Çelik D. Efficacy of three rotary NiTi instruments in removing gutta-percha from root canals. Int Endod $\mathrm{J}$, $2008 ; 41: 191-196$. 